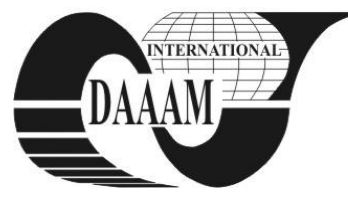

\title{
ARRHENIUS EQUATION PARAMETERS IDENTIFICATION FROM TEMPERATURE PROFILES
}

\author{
MACKU, L[ubomir]
}

\begin{abstract}
The article describes an alternative method of determining the rate constants for chemical reactions of first order. Specifically, the determination of Arrhenius equation parameters, ie activation energy and pre-exponential factor from the measured temperature curves. The advantage of this approach is that there is no need to determine the immediate reactants concentration by its measurement. Knowledge of the rate constant may significantly improve safety and control of specific processes
\end{abstract}

Key words: rate constant, exothermic process, semi-batch reactor, identification, simulation

\section{INTRODUCTION}

In the process control area, there are a lot of systems with nonlinear behaviour. Specific case of such nonlinear system is an exothermic chemical reactor. The reactor nonlinearity can arise from different reasons. One of them is the changeable reaction speed, which depends on the reactants concentration and the in-reactor temperature. The second dependence is described by Arrhenius equation. Knowledge of the Arrhenius equation parameters is a key for correct mathematical model composition and also for safe and successful control. Influence of this equation on the batch process control and possibility of its parameters determination are studied in this paper.

\section{MODEL OF A SEMI-BATCH REACTOR}

Influence of reaction kinetics on an exothermic process running a first order reaction and a mathematical model of such system is described in this section.

The following figure shows a chemical semi-batch reactor with initial filling $m_{B}[\mathrm{~kg}]$ given by the solution of chemicals. A reactant causing an exothermic chemical reaction to run is fed into the reactor to control the developing heat. The temperature has to stay under a certain critical level; otherwise the reactor could be destroyed. It is also desirable to utilize the whole capacity of the reactor to process the maximum amount of chemicals in the shortest possible time (higher temperature is desirable).

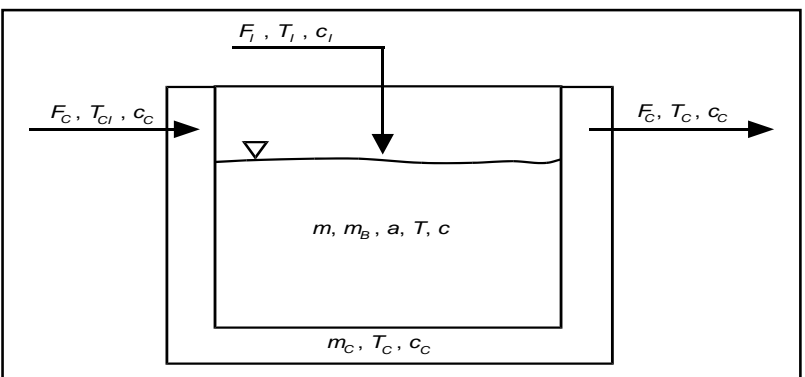

Fig. 1. Exothermic semi batch reactor scheme process safety

The mathematical model of such system can be written by equations (1)-(4).

$$
\begin{gathered}
\frac{\mathrm{d} m(t)}{\mathrm{d} t}=F_{I} \\
\frac{\mathrm{d} a(t)}{\mathrm{d} t}=\frac{F_{I}}{m(t)}-A \cdot e^{-\frac{E}{R \cdot T(t)}} \cdot a(t) \\
\frac{\mathrm{d} T(t)}{\mathrm{d} t}=\frac{F_{I} \cdot c_{I} \cdot T_{I}}{m(t) \cdot c}+\frac{A \cdot e^{-\frac{E}{R \cdot T(t)}} \cdot \Delta H_{r} \cdot a(t)}{c}- \\
-\frac{K \cdot S \cdot T(t)}{m(t) \cdot c}+\frac{K \cdot S \cdot T_{C}(t)}{m(t) \cdot c} \\
\frac{\mathrm{d} T_{C}(t)}{\mathrm{d} t}=\frac{F_{C} \cdot T_{C I}}{m_{C}}+\frac{K \cdot S \cdot T(t)}{m_{C} \cdot c_{C}}- \\
-\frac{K \cdot S \cdot T_{C}(t)}{m_{C} \cdot c_{C}}-\frac{F_{C} \cdot T_{C}(t)}{m_{C}}
\end{gathered}
$$

The used model was set up for the chromium waste recycle process (Kolomazník et al., 2007; Macků \& Sámek 2010), so for simulations were taken the parameters of this process. Here $m$ is the total weight of reaction components in the reactor, $a$ is the mass concentration of the reaction component in the reactor, $c$ is the specific heat capacity of the reactor content; $T$ is the temperature of the reactor content. $F_{I}, T_{I}$ and $c_{I}$ is the reaction component input mass flow rate, temperature and specific heat capacity. $F_{C}, T_{C l}, T_{C}, c_{C}$ and $m_{C}$ is the cooling water mass flow rate, input temperature, output temperature, specific heat capacity and weight of the cooling water in the cooling system of the reactor, respectiveely. Other constants: $A$ pre-exponential factor, $E$ activation energy, $\mathrm{R}$ gas constant, $\Delta \mathrm{Hr}$ heat of reaction, $K$ heat transfer coefficient, $S$ heat transfer surface.

\subsection{The rate constant}

In equations (2) and (3) is included influence of temperature and reaction component mass concentration on the reaction rate. The temperature dependence is defined by Arrhenius equation (5), were $k$ is the rate constant:

$$
k=A e^{-\frac{E}{R T[t]}}
$$

The rate constant causes an accumulation of the reaction component in the reactor without corresponding temperature rise. Then, the level of concentration which starts the reaction is reached and the reaction runs very fast. The temperature rises as well and causes the reaction runs even faster. Thus, if the amount of non-reacted reaction component in the reactor is too 
high, the temperature became uncontrollable and we can't avoid its overshooting. An example of the temperature overshoot caused by accumulation can be seen in figure 2 . Here you can see a temperature overshoot over $373 \mathrm{~K}$, which was caused by the accumulation of the reaction component. The corresponding mass concentration is depicted in the figure 3 . The plots were obtained by a two step control simulation. The actuating signal switch-off was set on $370 \mathrm{~K}$, the switch-on was set on $365 \mathrm{~K}$. It was impossible prevent the temperature overshooting and simultaneously to trace the desired value $373 \mathrm{~K}$. In the steady state (from approximately $t=2000$ s) was the control performance satisfactory. So, it is necessary to take into account the mass concentration to prevent the temperature overshooting.

With the knowledge of the previously mentioned model (that means also the knowledge of the rate constant) we can find the safe value of the reaction component concentration during the start-up part of the process control and so prevent the temperature overshooting. It is important to know the velocity constant parameters to be able satisfactory control like these processes. As far as we use the very same chemicals for processing, there is no generally problem. We can do the identification once and the parameters are always the same. But in case we plan processing wider range of chemicals, or the mixture properties are changeable in time, it is necessary to perform on-line velocity coefficient identification to process safely different mixture types.

\section{RATE CONSTANT IDENTIFICATION}

For the rate constant identification the formula in equation (6) was derived:

$$
k=\frac{d T}{d t} \frac{C}{V \Delta H_{r} c}=\frac{d T}{d t} \frac{C}{\Delta H_{r} n}
$$

Individual symbols: derivation $d T / d t$ means a tangent direction (see figure 4), $C\left[\mathrm{~J}^{-\mathrm{K}^{-1}}\right]$ - system thermal capacity, $V\left[\mathrm{~m}^{3}\right]-$ volume, $c\left[\mathrm{~mol} . \mathrm{m}^{-3}\right]$ - molar concentration, $n[\mathrm{~mol}]-$ the number of mole.

As can be seen from the formula (6) we need to know the in-reactor chemicals volume $V$ and concentration of reactant causing the heat development $c$ (or the number of mole $n$ instead) to determine the rate constant. Further it is necessary to know also the heat of reaction $\Delta H r$, system thermal capacity $C$ and the temperature tangent direction $d T / d t$.

The chemicals volume and the starting concentration are usually known. The system (reactor) thermal capacity must be determined, but only once. Finally the temperature tangent direction may be obtained from the measured temperature time dependence. With the help of the formula (6) we can use an in-reactor temperature profile to find the rate constant directly from the process.

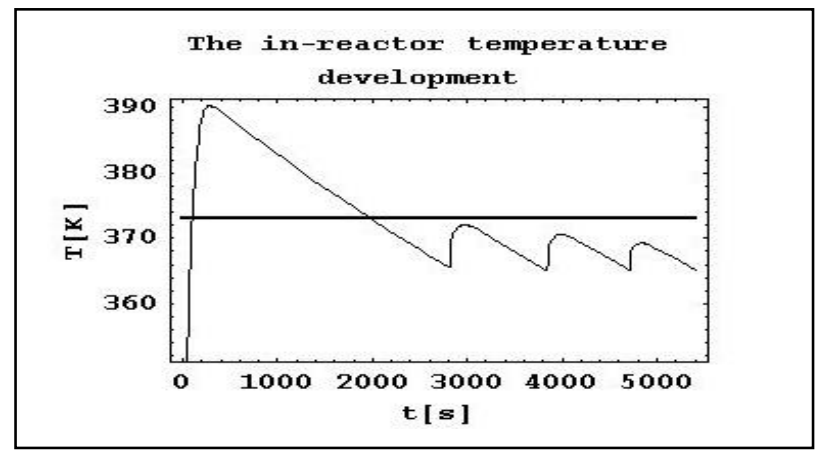

Fig. 2. The temperature overshoot caused by the reactant accumulation

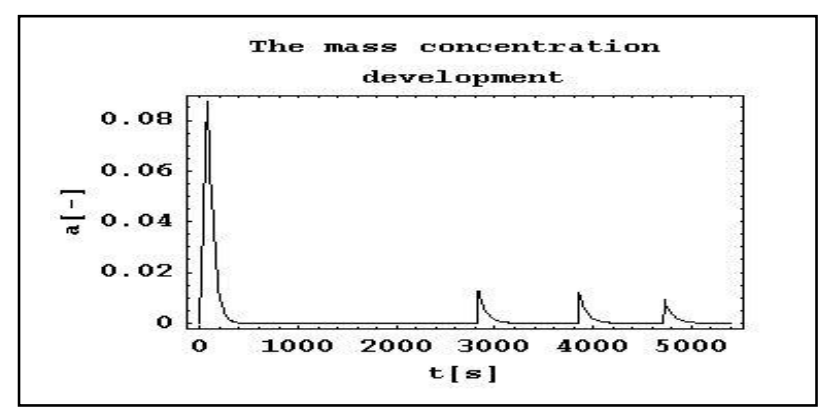

Fig. 3. The mass concentration development

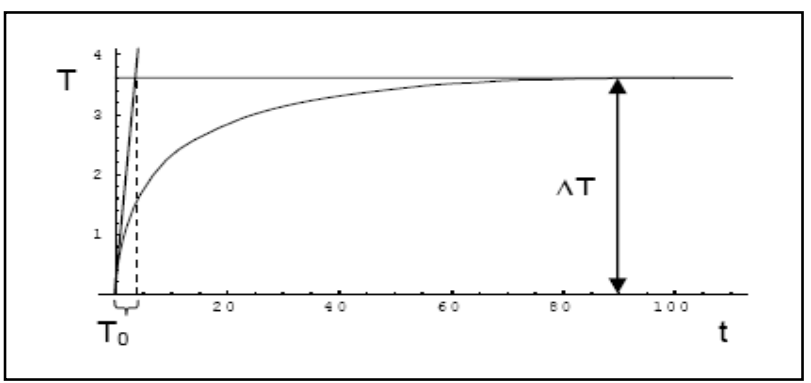

Fig. 4. An example of reaction temperature time dependence

\section{CONCLUSION}

The rate constant knowledge can help us to set up a precise system model and to apply a suitable control method. With a system model even simple control methods can be used to control some specific batch reactors. On the above mentioned system some control methods had been applied, which were described in articles (Sámek \& Macků, 2007; Gazdoš \& Macků, 2008; Novosad \& Macků, 2010). Very powerful seems to be for example predictive control using neural networks (Sámek \& Macků, 2007).

\section{ACKNOWLEDGEMENTS}

This work was supported by the Ministry of Education, Youth and Sports of the Czech Republic under the Research Plan No. MSM 7088352102 and by the European Regional Development Fund under the project CEBIA-Tech No. CZ.1.05/2.1.00/03.0089.

\section{REFERENCES}

Kolomazník, K., Adámek, M. \& Uhliřrová, M. (2007). Potential Danger of Chromium Tanned Wastes, Proceedings of the 5th IASME/WSEAS International Conference on Heat Transfer, Thermal Engineering and Environment, IASME/WSEAS, pp. 137-141

Macků, L. \& Sámek, D.(2010). Two step, PID and model predictive control using artificial neural network applied on semi-batch reactor, WSEAS Transactions on Systems, Vol. 9, No. 1, pp. 1039-1049, ISSN 1109-2777

Sámek, D. \& Macků, L. (2007). Simulation of model predictive control of semi-batch reactor, Proc. Int. Symp. on Systems Theory SINTES 13, Oct.18-20, Craiova, Romania, pp. 180185, University of Craiova, Craiova

Gazdoš, F. \& Macků, L.(2008). Analysis of a semi-batch reactor for control purposes, Proceedings of 22nd European Conference on Modelling and Simulation ECMS 2008, Nicosia, Cyprus, pp. 512-518, ISBN 978-0-9553018-5-8

Novosad, D. \& Macku, L. (2010). Ziegler-Nichols controller with online identification versus PID controller comparison, Annals of DAAAM for 2010 \& Proceedings of the 21st International DAAAM Symposium, pp 1017-1018, ISBN 978-3-901509-73-5, ISSN 1726-9679 